\title{
North Pacific Month to Month SST Changes
}

\author{
Kern E. Kenyon \\ 4632 North Lane, Del Mar, USA \\ Email: kernken@aol.com
}

Received 29 July 2014; revised 8 August 2014; accepted 20 August 2014

Copyright (C) 2014 by author and Scientific Research Publishing Inc.

This work is licensed under the Creative Commons Attribution International License (CC BY). http://creativecommons.org/licenses/by/4.0/

(c) (7) Open Access

\begin{abstract}
Month to month changes in the SST of the North Pacific, on the eastern side at mid-latitudes, are studied based on 30 years of ship-injection temperatures. Along both 40 and $35 \mathrm{~N}$ the SST maximum shifts west in summer, but it starts west at $35 \mathrm{~N}$ two months sooner than at $40 \mathrm{~N}$. In July the maximum at $40 \mathrm{~N}$ is at the same location as the maximum at $35 \mathrm{~N}$ was in June: $155 \mathrm{~W}$. Since the longitudinal SST maximum in the eastern North Pacific has previously been identified as the signature of a very wide, warm and sluggish current permanently flowing northeast off California, the month to month SST changes are used to estimate its mean speed: $10-20 \mathrm{~cm} / \mathrm{sec}$. Also the month to month SST changes indicate that in summer a new body of warm water goes north, in a pulselike movement, to the west of the existing wide warm current. This is consistent with the need of the western equatorial ocean to export more heat northward out of the tropics in summer due to the increased absorption of solar radiation in the surface layer in that season.
\end{abstract}

\section{Keywords}

North Pacific SST, Longitudinal Maximum, Month to Month Changes

\section{Introduction}

Seasonal variations of the sea surface temperature of the North Pacific have been described recently [1]. For example, north of $20 \mathrm{~N}$ the highest values, in the long-term mean, occur in August and September in broad bands of the open ocean. In addition there is a small patch off the west coast of the US where the highest temperatures of the year are to be found in October! Coldest annual temperatures mostly take place in March and April. Thus there are significant time lags at mid-latitudes between when the sun is farthest north and when the sea surface is warmest as well as between when the sun is farthest south and the sea surface is coldest.

These conclusions are based on an extensive set of ship-injection temperatures collected during thirty years extending from coast to coast. There are literally millions of observations contained in this data set, which is formatted in five degree latitude/longitude squares and one month intervals, starting in 1947. Features of the 
seasonal variations were interpreted in terms of changes, mainly in horizontal position, of a very wide, warm and sluggish surface current permanently flowing northeast off California.

With the help of the same data base it is possible to say a few things about month to month SST changes in the North Pacific, and that is the purpose of the present essay. This is a natural next step to take, but to my knowledge month to month SST changes have never been studied before for the North Pacific. There are no preconceived expectations existing for how the results might turn out. However, since a connection has been shown between the longitudinal SST maximum and the NPH (North Pacific High), it could become important to know more about these month to month SST changes in connection with weather variations that pass across the US [2].

Therefore, once again the unifying thread used below is the large-scale longitudinal maximum in SST at mid-latitudes, usually on the eastern side of the ocean, which has been identified as the signature of a very wide warm surface current. In fact, this SST maximum appears to locate the approximate east/west mid-point of the northeastward flow. And the NPH usually sits right on top of it.

One of the main physical functions of the wide warm current, and the colder return flow underneath, has been conjectured to be to conduct some of the excess solar heat absorbed mainly at low latitudes by the North Pacific at all times of the year, but especially in the northern summer, from tropical latitudes to higher latitudes in order to help maintain the earth's heat balance [3]. It is clear that heat must be transported out of the tropics because the surface temperatures of the western equatorial waters are no higher in summer than in winter [4] in spite of the fact that more solar energy per unit area and per unit time must get absorbed in the upper $100 \mathrm{~m}$ in summer than in winter. Assuming the tropical seas do not give up all that excess heat directly to the atmosphere, then it must be carried northward by ocean currents.

How can the northward oceanic heat flow increase in the summer since the depth scale of the warm flow cannot change, it is tied to the maximum depth of penetration of sun light, which is about $100 \mathrm{~m}$ ? Possibly the average speed of the current might increase in summer due to the stronger southward surface temperature gradient in summer that is related to the thermal driving force behind the warm/cold surface and near surface circulation. To check up on this idea would be difficult because of the expected sluggishness of the flow [5] caused by a cold source and a warm source at nearly the same level (sea level) but separated by a large horizontal distance (tropics to the sub-arctic).

However, there may be another way that the ocean can increase its net northward heat flux in summer, as suggested by the ship-injection SST data. Either the warm surface current could significantly and rather suddenly widen to the west in early summer [there being no room to the east due to the presence of the North American continental boundary]. Or perhaps equally likely is the possibility that a separate seasonal pulse of warm water could start moving northward in summer temporarily flowing alongside and to the west of the existing permanent northeastward flow (perhaps merging with it) that is in place at all times of the year. Untangling these two options in any given year may not be conclusive with presently available data. In any case, what would trigger the additional pulse of warm water to move north must be a burst of cold water coming south in or near the surface layer, i.e. probably just below it. Such a burst of cold water would not always directly be reflected in the SST data, which documents mostly the position and movement of the warm water.

That there is a return flow of colder water under the wide warm current of the eastern North Pacific is made known by the permanent feature of the shallow salinity minimum [6], where relatively low salinity acts as a dye marking a layer of colder southward flow just underneath the warm northward current at mid-latitudes. Farther to the north at the sea surface is the source of the low salinity water because at that location precipitation exceeds evaporation.

What follows in Section 2 is a straightforward calculation of the month to month changes in longitude of the SST maximum along $40 \mathrm{~N}$, where it is found that the standard deviations are significantly large in the summer months during the westward seasonal migration of the SST maximum. This calculation suggests that in early summer an additional rather irregular pulse of warm water heads north to the west of the permanent northeastward flow.

Further evidence of the extra northward flow of warm water in summer is sought in Section 3 by showing that the mean westward migration of the SST maximum along $35 \mathrm{~N}$ starts two months before the similar westward migration along $40 \mathrm{~N}$. With some assumptions these surface temperature observations then allow an estimate to be made of the mean northward flow speed, making the word "sluggish" more quantitative (Section 4). 


\section{Month to Month}

Along $40 \mathrm{~N}$ the longitude of the SST maximum in the eastern part of the ocean was read and recorded for each month for 30 years, beginning with 1947. Then the longitude differences between all consecutive pairs of months was computed: for example J-F, F-M,... etc., where $\mathrm{J}=$ January, $\mathrm{F}=$ February, $\mathrm{M}=$ March... These longitude differences were then corrected by subtracting out the 30 year average month to month longitude differences for the same pairs of months in order to filter out the normal seasonal variation. Finally, the standard deviations of the corrected month to month changes in the longitude of the SST maxima were formed (Figure 1).

On the vertical axis of Figure 1 are the standard deviations in whole degrees of longitude at $40 \mathrm{~N}$. Remember that the longitude of the SST maximum could only be read to the nearest five degrees, due to the format of the ship-injection temperatures. Therefore, standard deviations of five degrees or less have no significance. On the horizontal axis are the consecutive month to month pairs.

What Figure 1 exhibits is that in the summer months the standard deviations rise to about three times those of the noise level (5 degrees). Month to month variations in the longitude of the SST maximum are largest from June through September over the given period. Since the smooth seasonal signal has been subtracted out, Figure 1 suggests a pulse like or episodic flow of additional warm water in the summer months, which presumably comes from the southwest.

Month to month changes in temperature at the location of the longitudinal SST maximum are not significant; they are $1 \mathrm{C}$ or less for all pairs of months [Ship-injection temperatures in those years were based on thermometers that can only be read to the nearest $1 \mathrm{~F}$. Therefore, east/west positional changes, rather than temperature changes, characterize the month to month variations in the SST at mid-latitude on the eastern side of the ocean.

Figure 2 shows the 30 year average temperature at the SST maximum along $40 \mathrm{~N}$. It is not the monthly mean temperature at a fixed location, but rather following the maximum throughout its seasonal migration east and west. Figure 2 displays a distinctive seasonal variation of the mean SST at the longitudinal maximum along 40 $\mathrm{N}$. There is a regular almost sinusoidal change in surface temperature with a minimum in March and a maximum in August, the total range being about $9 \mathrm{C}$. The minimum might be described as being shallower and the maximum more peaked than an exact sinusoid would be.

Since it has been proposed that the surface water surrounding the longitudinal SST maximum along $40 \mathrm{~N}$ has its source in the western tropical North Pacific (Kenyon, 2013), where the surface temperature is about $28 \mathrm{C}$ year round, by the time these waters have reached $40 \mathrm{~N}$ there has been a good deal of heat lost to the atmosphere even in August according to Figure 2: i.e. a seven degree drop in temperature. And it is interesting that the SST maximum at $40 \mathrm{~N}$ has such a strong seasonal signal whereas the source region basically has none. Evidently, in traveling from the tropics to mid-latitudes considerably more heat is transferred from the ocean's surface layer to the atmosphere in winter than in summer, at least in the wide area surrounding the longitudinal SST maximum. In the mean the winter SST in Figure 2 is $16 \mathrm{C}$ degrees lower than it was at the source.

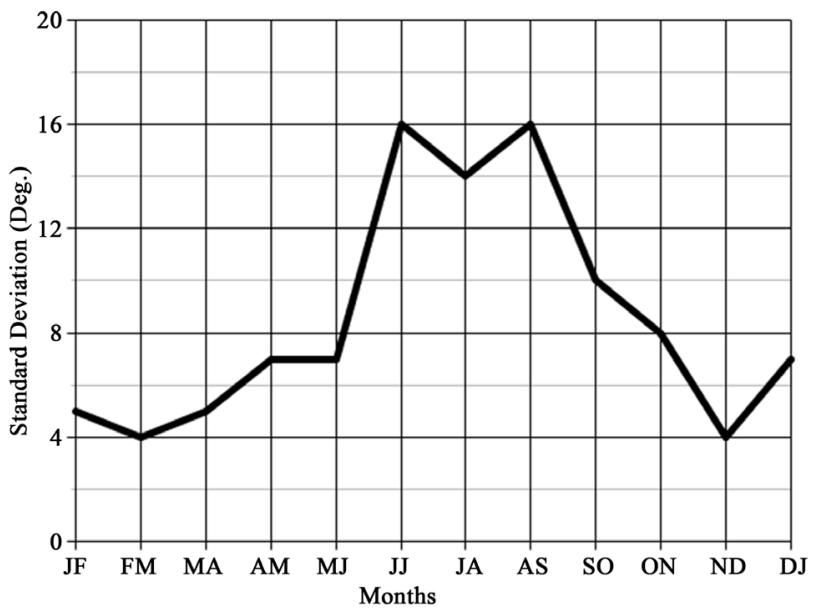

Figure 1. Standard deviations (degrees of longitude) of the month to month changes in longitude of the SST maximum at $40 \mathrm{~N}$ plotted against month pairs. Based on 30 years of ship-injection data. 


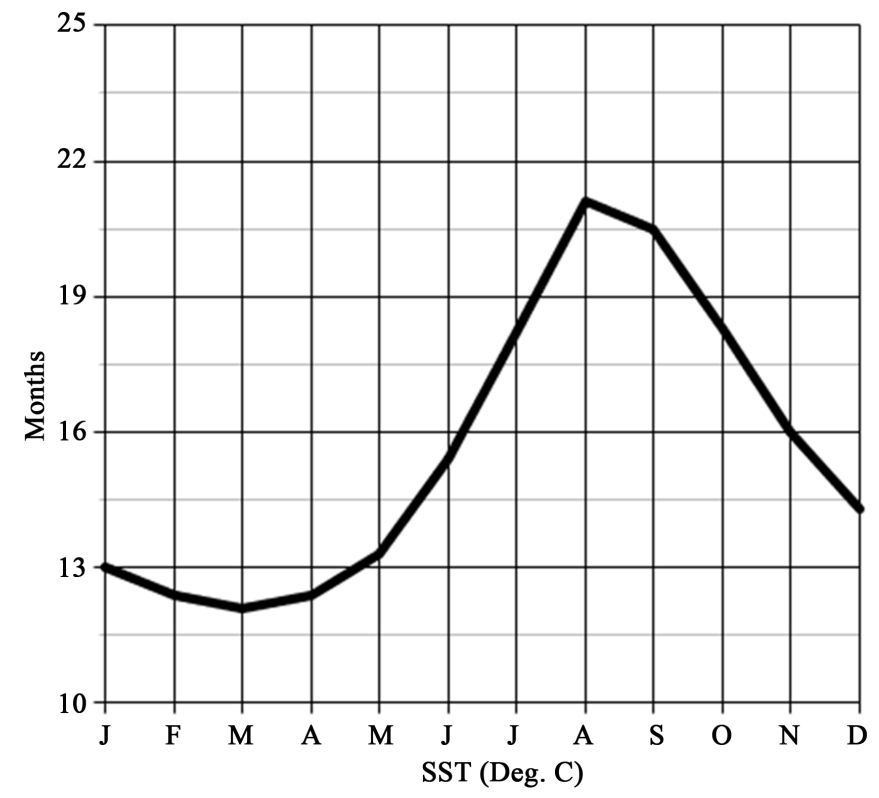

Figure 2. 30 year mean temperatures (Deg. C) at the SST maximum along 40 $\mathrm{N}$ plotted against month.

\section{Spring into Summer}

One feature of the month to month variation of the SST in the North Pacific, not mentioned above, has only been noticed recently. The east/west migration of the longitudinal maximum in sea surface temperature throughout the year has been documented at 35 and $40 \mathrm{~N}$ : it moves west in summer and returns east in fall (Kenyon, 1981). What has not been said earlier is that the systematic westward movement starts at $35 \mathrm{~N}$ significantly before it begins at $40 \mathrm{~N}$. This is true in the 30 year average as well as in individual years. Typically the maximum at $40 \mathrm{~N}$ starts west between June and July whereas the maximum at $35 \mathrm{~N}$ moves systematically west two months earlier, starting between April and May, and continues west from May to June (Figures 3-5).

From late fall through winter and into early spring the location of the longitudinal maximum of the SST does not move. Along $40 \mathrm{~N}$ it is at $140 \mathrm{~W}$ and along $35 \mathrm{~N}$ it is at $147.5 \mathrm{~W}$. In any given month, and in the long term mean, the maximum at $35 \mathrm{~N}$ is always west of that at $40 \mathrm{~N}$ implying that the flow surrounding the maxima between 35 and $40 \mathrm{~N}$ is generally northeast. Then in April the maximum at $35 \mathrm{~N}$ starts its move to the west and later in June the maximum at $40 \mathrm{~N}$ moves west. By November the $40 \mathrm{~N}$ maximum has returned to its most eastern position whereas the $35 \mathrm{~N}$ maximum requires another month to get all the way back east again.

What is going on here is a periodic phenomenon, the summer migration of the longitudinal SST maximum, because it happens once a year and every year. However, one would not characterize it as being perfectly sinusoidal. The period of time that the maximum is away from its winter position is four months at $40 \mathrm{~N}$ but six months at $35 \mathrm{~N}$. By contrast the ultimate forcing function, the absorption in the ocean of short wave radiation from the moving sun, is sinusoidal.

For the months of April, May and June the 30 year means of the SST are plotted in Figures 3-5 against longitude for both 35 and $40 \mathrm{~N}$ on three graphs, one for each month. The same temperature scale is used for convenience (so the $40 \mathrm{~N}$ curve lies below the $35 \mathrm{~N}$ curve in each figure, not above as on a map). It can be seen in these figures that the location of the eastern maximum at $40 \mathrm{~N}$ does not move away from $140 \mathrm{~W}$. However, in July it jumps west 15 degrees of longitude (not shown). On the other hand, the analogous maximum at $35 \mathrm{~N}$ starts moving west between April and May. This feature appears to be significant and it is what would be expected if an additional body of warm water were to move northward away from the tropics: the temperature signal should cross $35 \mathrm{~N}$ first and $40 \mathrm{~N}$ second.

\section{Discussion}

From the time delay of two months, in the 30 year mean, between the start of the westward migration of the SST 


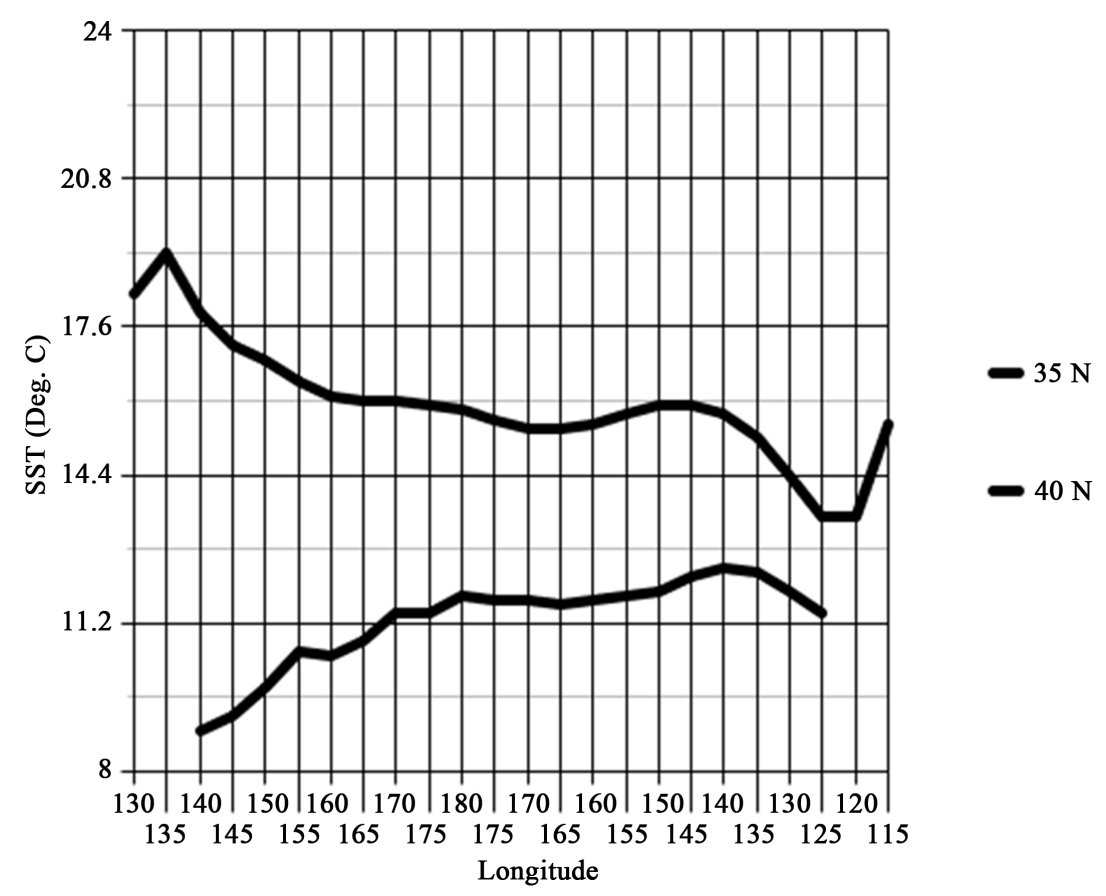

Figure 3. 30 year mean SSTs (Deg. C) plotted against longitude at $35 \mathrm{~N}$ (top) and 40 $\mathrm{N}$ (bottom) for April. California is to the right, Japan to the left.

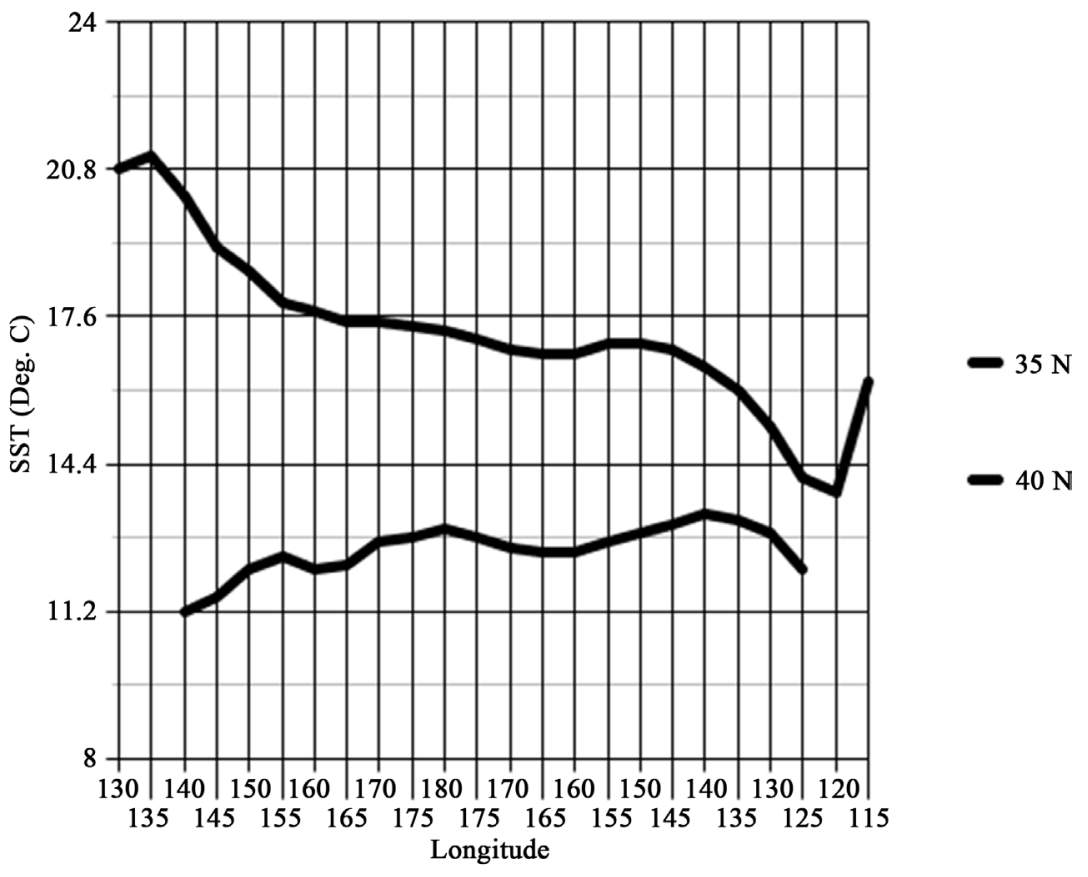

Figure 4. Same as Figure 3 except for May.

maximum at $35 \mathrm{~N}$ and the start of the westward migration at $40 \mathrm{~N}$, and the distance of five degrees of latitude, a northward speed for the temperature signal to get from $35 \mathrm{~N}$ to $40 \mathrm{~N}$ can be estimated. It is $10 \mathrm{~cm} / \mathrm{sec}$. What is the meaning of such an estimate? Many cautions need to be stated. First, a long term mean is tricky because it involves averaging many individual cases. From this point of view the estimate might tend to be a low one. If the estimate is to be associated with a flow speed, it will be low also because the mean flow speeds in the area are usually northeast instead of straight north, as inferred from the SST data and assumed in the estimate. 


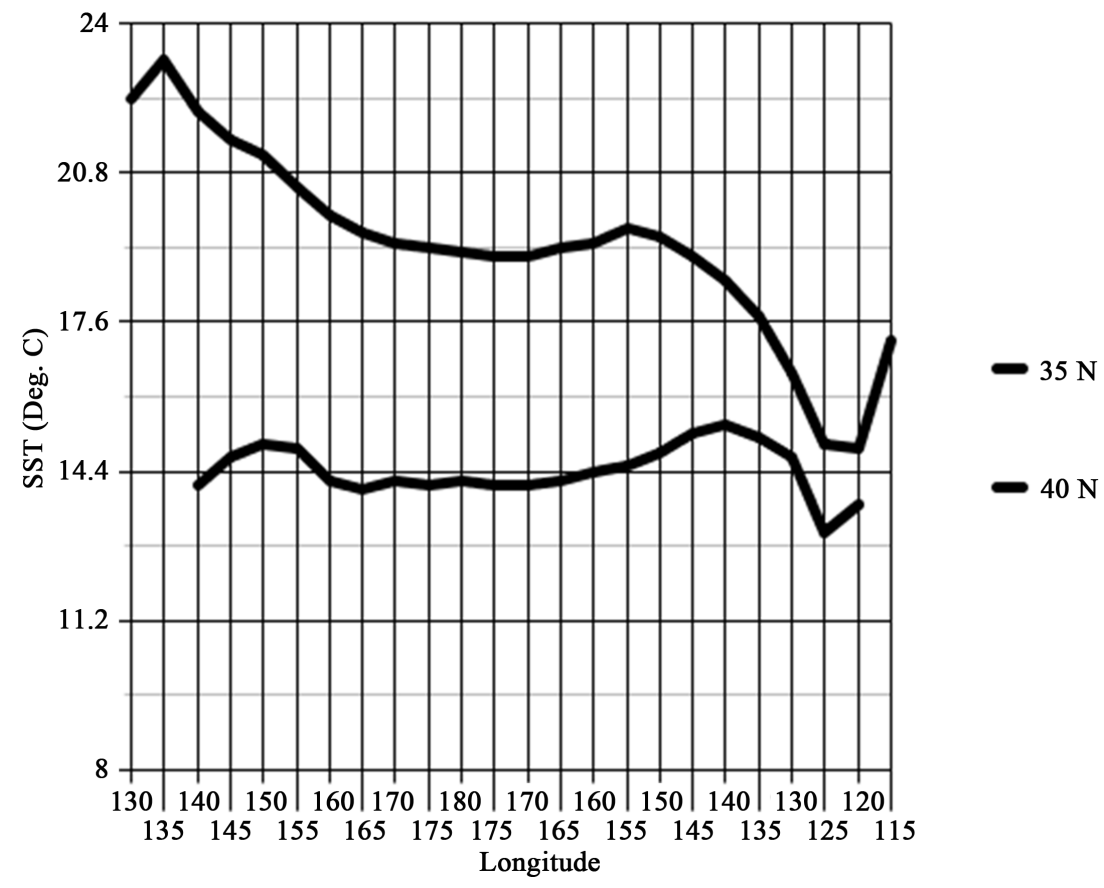

Figure 5. Same as Figure 3 except for June.

Here is another complication. Figures 3-5 show that the SST maximum at $35 \mathrm{~N}$ moves west 5 degrees of longitude between April and May and then another 2.5 degrees west between May and June, whereas the SST maximum at $40 \mathrm{~N}$ does not move west at all during this time period but then does move west 15 degrees of longitude between June and July. Interpreting the westward movement of a temperature pattern (longitudinal variation) in terms of a northward (or northeastward) movement of fluid would seem to be an impossible task on the face of it.

There is one potential confusion that is not an occasion for much discussion. Even though the longitudinal temperature patterns at 35 and $40 \mathrm{~N}$ in the eastern North Pacific look wave-like, the SST data do not suggest that a wave phenomenon lies behind them. So that option can be dropped from consideration right away. No wave phase or group velocity needs to be sought.

Furthermore, the warm water is losing heat to the atmosphere in going from 35 to $40 \mathrm{~N}$, and the amount of heat lost may vary with longitude, perhaps only gradually though, which could have an effect on the longitudinal shape of the temperature signal. However, at least the longitudinal maximum character of the SST stays intact between 35 and $40 \mathrm{~N}$.

Another possible sequence of events comes to mind. Suppose that in the mean sometime before April a new body of warm water is pushed up from the south outside or alongside the permanent wide warm current to its east. As it crosses $35 \mathrm{~N}$ this new body of warm water begins to influence the shape of the longitudinal SST maximum, mainly the western limb including the maximum itself, by gradually moving the maximum westward from April through June. Then in July the SST maximum at $40 \mathrm{~N}$ has shifted 15 degrees of longitude to the west from 140 to $155 \mathrm{~W}$. That puts it straight north of where the maximum at $35 \mathrm{~N}$ was in June (Figure 5). So if the new warm water surrounding the maximum went straight north from $35 \mathrm{~N}$ in June to $40 \mathrm{~N}$ in July, the mean speed of flow would have to be $20 \mathrm{~cm} / \mathrm{sec}$, double the estimate given above (i.e. five degrees of latitude in one month instead of in two months).

Although the most recent 30 plus years of ship-injection temperatures for the North pacific, if they exist, have not been available to me, my guess is that the above conclusions would not change in any significant way were they to be incorporated into present analyses.

\section{Conclusion}

Month to month changes in the SST of the North Pacific along 35 and $40 \mathrm{~N}$ are described using ship-injection 
temperatures collected over a 30-year period. These changes are related to the longitudinal SST maximum in the eastern North Pacific, which has been identified as the signature of a very wide warm surface current flowing sluggishly northeast off the coast of California. During late fall to early spring the maximum stays fixed at both 35 and $40 \mathrm{~N}$. Between April and May the maximum at $35 \mathrm{~N}$ starts its migration west and then two months later, between June and July, the maximum at $40 \mathrm{~N}$ goes west. In July the maximum at $40 \mathrm{~N}$ is straight north of where the maximum at $35 \mathrm{~N}$ was in June. Using only SST data a mean northward speed of flow is estimated to be 10 $20 \mathrm{~cm} / \mathrm{sec}$. In the summer months the standard deviations of the east/west positions of the SST maximum are significantly large, suggesting that an increased episodic northward flow of warm water is occurring just west of the permanent wide warm current. This is consistent with the need for the ocean to enhance its net northward heat flux due to the increased absorption of solar radiation in summer.

\section{References}

[1] Kenyon, K.E. (2013) Seasonal Sea Surface Temperatures of the North Pacific. Natural Science, 5, 875-879. http://dx.doi.org/10.4236/ns.2013.58105

[2] Kenyon, K.E. (1999) North Pacific High: An Hypothesis. Atmospheric Research, 51, 15-34. http://dx.doi.org/10.1016/S0169-8095(98)00110-0

[3] Kenyon, K.E. (1981) A Shallow Northeastward Current in the North Pacific. Journal of Geophysical Research, 86, 6529-6536. http://dx.doi.org/10.1029/JC086iC07p06529

[4] US Hydrographic Office (1942) World Atlas of Sea Surface Temperatures. 2nd Edition, H. O. No. 225, US Navy, Washington DC.

[5] Neumann, G. and Pierson, W.J. (1966) Principles of Physical Oceanography. Prentice-Hall, Englewood Cliffs, 230233.

[6] Kenyon, K.E. (1978) The Shallow Salinity Minimum of the Eastern North Pacific in Winter. Journal of Physical Oceanography, 8, 1061-1069. http://dx.doi.org/10.1175/1520-0485(1978)008<1061:TSSMOT>2.0.CO;2 
Scientific Research Publishing (SCIRP) is one of the largest Open Access journal publishers. It is currently publishing more than 200 open access, online, peer-reviewed journals covering a wide range of academic disciplines. SCIRP serves the worldwide academic communities and contributes to the progress and application of science with its publication.

Other selected journals from SCIRP are listed as below. Submit your manuscript to us via either submit@scirp.org or Online Submission Portal.
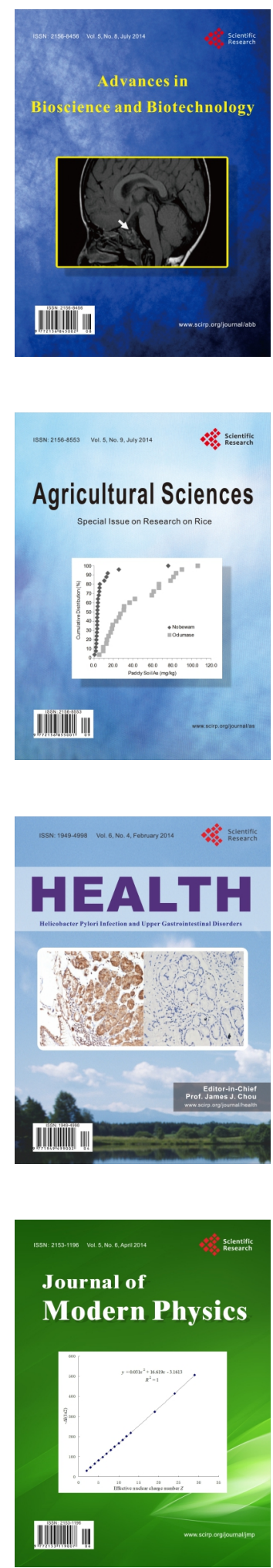
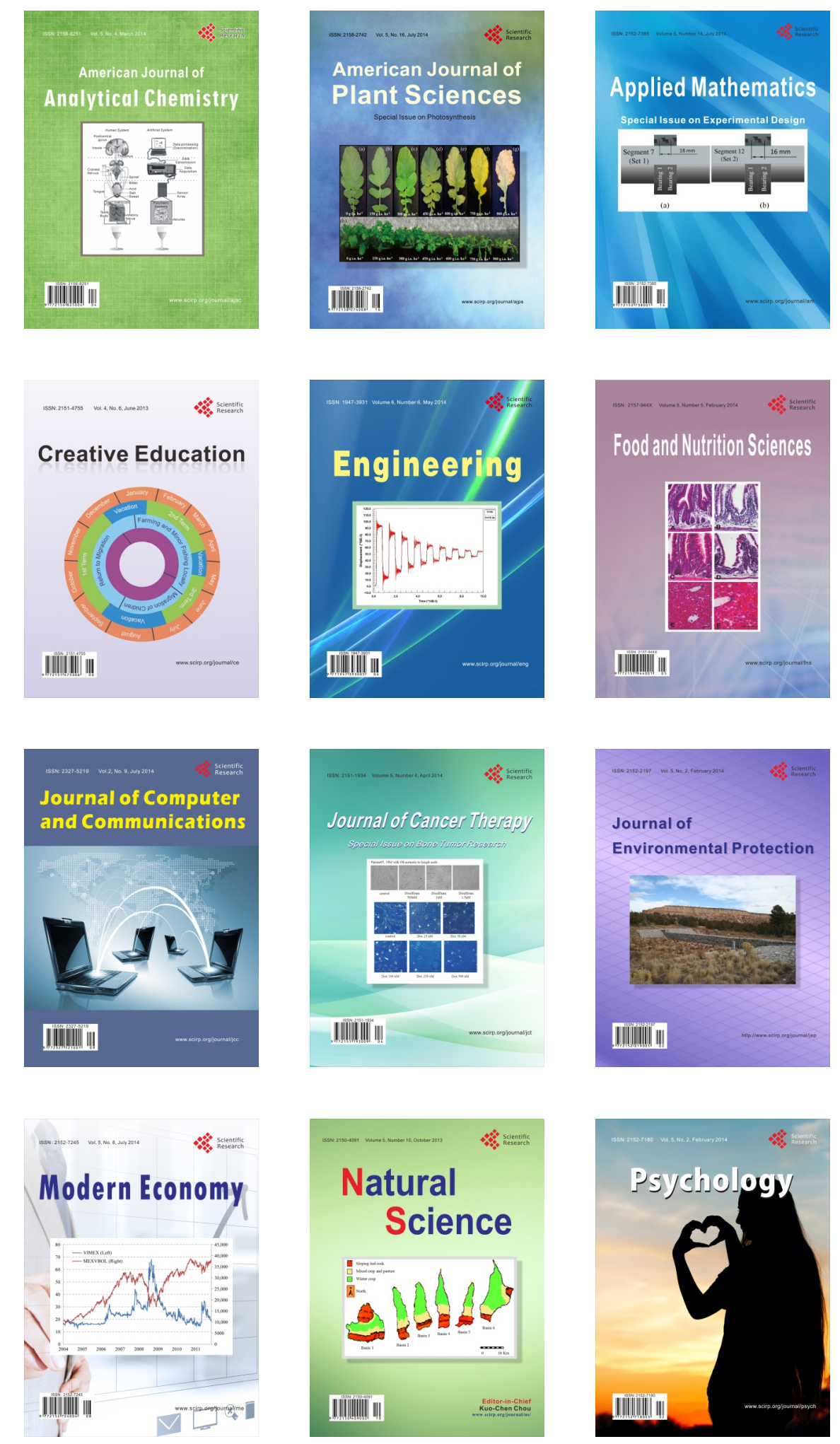